\title{
Vitamin D Upregulates Endothelin-1, ETBR, eNOS mRNA Expression and Attenuates Vascular Remodelling and Ischemia in Kidney Fibrosis Model in Mice
}

\author{
N. ARFIAN ${ }^{1}$, M. H. H. KUSUMA ${ }^{1}$, N. ANGGOROWATI ${ }^{2}$, D. B. NUGROHO ${ }^{3}$,

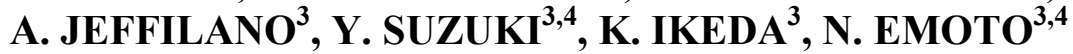

${ }^{1}$ Department of Anatomy, Faculty of Medicine, Public Health and Nursing, Universitas Gadjah Mada, Yogyakarta, Indonesia, ${ }^{2}$ Department of Anatomical Pathology, Faculty of Medicine, Public Health and Nursing, Universitas Gadjah Mada, Yogyakarta, Indonesia, ${ }^{3}$ Department of Clinical Pharmacy, Kobe Pharmaceutical University, Kobe, Japan, ${ }^{4}$ Division of Cardiovascular Medicine, Department of Internal Medicine, Kobe University Graduate School of Medicine, Kobe, Japan

Received November 30, 2017

Accepted March 23, 2018

\section{Summary}

We examined the upregulation of ET-1/ETBR/eNOS signaling in renoprotective effect of vitamin $D$ in kidney fibrosis model in mice using unilateral ureteral obstruction (UUO). One group was treated with intraperitoneal injection of $0.125 \mathrm{mg} / \mathrm{kg}$ of Calcitriol (UUO+VD). Vascular remodeling was quantified based on lumen area and lumen/wall area ratio (LWAR) of intrarenal arteries using Sirius Red staining. ET-1, ETBR, eNOS, CD31 and VEGF mRNA expressions were quantified using qRT-PCR. Focusing on endothelin-1 (ET-1) signaling in endothelial cells (EC), siRNA of ET-1 was performed in human umbilical vein endothelial cells (HUVEC) for reducing ET-1 expression. Then HUVECs were treated with and without $100 \mathrm{nM}$ Calcitriol treatment in hypoxic and normoxic conditions to elucidate ET-1/eNOS signaling. Our in vivo study revealed vascular remodeling and renal ischemia attenuation after Calcitriol treatment. Vascular remodeling was attenuated in the UUO+VD group as shown by increasing lumen areas and LWAR in intrarenal arteries. These findings were associated with significant higher CD31 and VEGF mRNA expression compared to the UUO group. Vitamin $D$ treatment also increased ET-1, ETBR and eNOS mRNA expressions. Our in vitro study demonstrated Calcitriol induced ET-1 and eNOS mRNA expressions upregulation in HUVEC under normoxic and hypoxic condition. Meanwhile, siRNA for ET-1 inhibited the upregulation of eNOS mRNA expression after Calcitriol treatment. Vitamin D ameliorates kidney fibrosis through attenuating vascular remodeling and ischemia with upregulating ET-1/ETBR and eNOS expression.

\section{Key words}

Kidney fibrosis • Endothelin-1 • Vitamin D • Vascular remodeling - eNOS

\section{Corresponding author}

N. Arfian, Department of Anatomy, Faculty of Medicine, Public Health and Nursing, Universitas Gadjah Mada, Yogyakarta, Indonesia. Fax: +62-274 547730. E-mail: nur_arfian@ugm.ac.id

\section{Introduction}

Kidney fibrosis leads to end stage renal damage as a final common pathway of chronic kidney diseases (CKD). It is characterized by myofibroblast formation and renal ischemia (Asada et al. 2011). Unilateral ureteral obstruction (UUO), as a model of kidney fibrosis induces lumen tubular pressure elevation, epithelial injury and tubulointerstitial fibrosis (Chevalier et al. 2009, Nath 1992). Renal ischemia can be produced by renal fibrosis. In the 5/6-subtotal nephrectomy model, renal ischemia occurs due to reduction of angiogenesis and vascular endothelial growth factor (VEGF) (Kang et al. 2002). Capillary loss also occurs in renal fibrosis due to detachment of pericyte in renal microvascular myofibroblasts (Lin et al. 2008, Humphreys et al. 2010). Hemodynamic changing in CKD may induce arterial remodeling which is influenced by activation of the renin-angiotensin system (RAS), endothelin-1 (ET-1), 
endothelial dysfunction, oxidative stress and asymmetric dimethylarginine (ADMA), as well as the anti-aging molecule Klotho (Briet and Burns 2012).

ET-1, the most potent vasoconstrictor, plays a role in kidney physiology and pathology (VignonZellweger et al. 2012). ET-1 transgenic mice undergo spontaneous kidney fibrosis without hypertension (Hocher et al. 1997). ET-1 deletion from endothelial cells (EC) also has protective effects in acute kidney injury model from ischemic/reperfusion injury (Arfian et al. 2012). ET-1 and endothelin converting enzymes-1 (ECE-1) have been known to play roles in fibrosis of many organs due to diabetic induction and bleomycin treatment (Miyagawa et al. 2010, Widyantoro et al. 2010, Hartopo et al. 2013). ET-1 works with two types of G-protein coupled receptors, endothelin A receptor (ETAR) and endothelin B receptor (ETBR). ETAR induces vasoconstrictors, while ETBR induces vasodilators due to endothelial nitrite oxide synthase (eNOS) production (Zellweger et al. 2012). Reduction of NO synthases' expression plays a role in the mechanism of kidney diseases. Disruption of all NO synthases accelerates renal damage in UUO model (Morisada et al. 2010). eNOS knockout attenuates the improvement of diabetic nephropathy after using renin-angiotensin blocker (Kosugi et al. 2010). ET-1/ETBR with NO production from collecting ducts serves as renoprotective effects in regulating arterial pressure and sodium excretion (Ahn et al. 2004, Ge et al. 2006). On the other hand, ET-1 and ETAR activation in capillary vessels induces intrarenal artery remodeling in the kidney ischemia/reperfusion injury model. Reduction of ET-1 from EC reduces wall thickness and may be associated with ETAR reduction (Arfian et al. 2012). Reduction of NO might induce vasoconstriction produced by endothelial damage (Bonventre and Yang 2011). Vascular remodeling and kidney fibrosis have also been reported in mice with deletion of prolyl hydroxylase domain protein-2 from endothelial cells (Wang et al. 2017). Similar research has concluded that molecules which regulate vessel tonus balance such as ET-1 and NO influence vessel remodeling (Bourque et al. 2011, Ye et al. 2003).

Vitamin D has been reported to attenuate kidney fibrosis in UUO model due to reduction of myofibroblast formation, inflammation and tubular cell apoptosis (Arfian et al. 2016). Vitamin D regulates endothelin-1 and NO production in endothelial cell culture (MartínezMiguel et al. 2014), however the role of the interaction in the pathology of diseases has not been fully known yet. Here we reported ET-1/ETBR/eNOS upregulation in renoprotective effects of vitamin $\mathrm{D}$ and relate this finding to attenuation of vascular remodeling and ischemic conditions due to kidney fibrosis.

\section{Methods}

\section{Animal subjects and UUO models}

This study was done based on our previous result (Arfian et al. 2016). Male Swiss Webster mice (8-10 weeks old, $\mathrm{n}=15,30-50 \mathrm{~g}$ ) were used for the experiments. Ethical clearance was approved by the Ethical Committee of Faculty of Medicine, Public Health and Nursing, Universitas Gadjah Mada, Yogyakarta, Indonesia, with number KE/FK/29/EC/2016. Mice were housed in the Department of Anatomy, Faculty of Medicine, Public Health and Nursing, Universitas Gadjah Mada, with the light-dark cycle of 12:12 h, food and water ad libitum. UUO/ureter ligation was performed to induce kidney fibrosis. Briefly, mice were anesthetized with sodium pentobarbital $(0.1 \mathrm{mg} / \mathrm{kg}$ body weight). The right flank's region was opened, and the right ureter was visualized then double ligated, then cut between the ligation sides. Sham operation (SO) procedure was used for the control group with the same procedure except for ligating and cutting the ureter. Subjects were divided into 3 groups, i.e. $\mathrm{SO}$ ( $\mathrm{SO}+$ ethanol $0.2 \%, \mathrm{n}=6$ ), UUO (UUO + ethanol $0.2 \%, \mathrm{n}=6$ ), $\mathrm{UUO}+\mathrm{VD}$ (UUO + Calcitriol $0.125 \mu \mathrm{g} / \mathrm{kg}, \mathrm{n}=6$ ). Vitamin $\mathrm{D}$ dose was determined based on our previous result that confirmed there was no independent dose of vitamin $\mathrm{D}$ in attenuating kidney fibrosis. Vitamin D treatment was done with intraperitoneal injection of Calcitriol $\left(\right.$ Cayman $\left.^{\circledR}, 0453406-2\right)$ that was diluted with ethanol $0.2 \%$. Mice were euthanized at day 14 after operation.

\section{Kidney harvesting}

For kidney harvesting, mice were anesthetized with sodium pentobarbital $(0.1 \mathrm{mg} / \mathrm{kg}$ body weight, ip), then the abdomen and thorax were opened. Perfusion was done with $0.9 \% \mathrm{NaCl}$ from the left ventricle. Right kidney tissues were harvested, and one half side was kept in RNA Later (Ambion, 7021) for RNA extraction and the other half was fixated in normal buffer formalin for $24 \mathrm{~h}$, and used for the paraffin embedded tissue process.

Histological analysis of lumen areas in intrarenal arteries Paraffin sections were de-paraffinized, and 
stained with Sirius Red (SR) to quantify vessel lumen areas and lumen/wall area ratio (LWAR), and for assessment of vascular remodeling. Ten to fifteen intrarenal arteries with $10-50 \mu \mathrm{m}$ in diameter were captured and used for quantification of lumen areas and LWAR. Quantification was conducted using ImageJ software.

\section{HUVEC cell culture in ischemic conditions}

HUVECs were cultured in HuMedia added with antibiotic-antimycotic and $10 \%$ fetal bovine serum. siRNA ET-1 (Dharmacone, M-016692-02-0005, siGENOME EDN1) was performed using LipofectamineRNAimax (Invitrogen, 13778-075) mixed with Optimem based on manufacturer's instructions. A day after siRNA for ET-1, HUVEC were treated with $100 \mathrm{nM}$ Calcitriol and put in hypoxic bags. Hypoxic condition was induced for $30 \mathrm{~min}$ in the HUVECs culture using a hypoxic bag with an oxygenometer. Briefly, HUVEC were cultured in a $6 \mathrm{~cm}$ dish. Hypoxic bags with an oxygen absorbent device were prepared and we waited for them to reach less than $2 \%$ of oxygen content. Then, we put the dish (HUVEC with and without $100 \mathrm{nM}$ Calcitriol treatment) in the hypoxic bag for $24 \mathrm{~h}$. After that, RNA was extracted using Trizol and we quantified the mRNA expression of ET-1 and eNOS using RT-PCR.

RNA extraction, $C D N A$ making and real time-PCR (RT-PCR)

RNA was extracted from kidney tissue using Trizol (Invitrogen, 1559-018, Paisley, UK). cDNA was synthesized using ReverTra-Ace (TOYOBO Co., Ltd, TRT-101). Real Time PCR (RT-PCR) was done for examining the expression of the following genes: pre-pro-ET-1/ET-1 mRNA (forward, 5'-GCCACAGAC CAGGCAGTTAGA-3'; reverse, 3'-CACCAGCTGCTG ATAGATACACTTC-5'), eNOS (forward, 5'-GTCCTG CAAACCGTGCAGAG-3'; reverse, 3'-TGGGTGCGC AATGTGAGTC-5'), ETBR (forward, 5'-CATGCGCAA TGGTCCCAATA-3'; reverse, 3'-GCTCCAAATGGC CAGTCCTC-5'), ETAR (forward, 5'-GCTGGTTCCCTC TTCACTTAAGC-3'; reverse, 3'-TCATGGTTGCCA GGTTAATGC-5'), VEGF (forward, 5'-CAGTTCGAG GAAAGGGAAAGG-3'; reverse, 5'-CACGTCTGCGGA TCTTGGAC-3'), and GAPDH (forward, 5'-TTGCTG TTGAAGTCGCAGGAG-3'; reverse, 5'-TGTGTC CGTCGTGGATCTGA-3') was used as reference. Meanwhile we used the following genes for human prepro-ET-1/ET-1 mRNA (forward, 5'-CAGAGGAAC
ACCTAAGACAAACC-3'; reverse, 3'-GTGGGTCAC ATAACGCTCTC-5'), human eNOS (forward, 5'-GGC ATCACCAGGAAGAAGACC-3'; reverse, 3'-TCACTC GCTTCGCCATCAC-5') and GAPDH (forward, 5'-GCA CCGTCAAGGCTGAGAAC-3'; reverse 3'-TGGTGA AGACGCCAGTGGA-5').

\section{Statistical analysis}

Data were analyzed using SPSS 22 software for Windows. Data normality test was conducted using Shapiro-Wilk test and one-way ANOVA for normal data distribution and Kruskal-Wallis test for abnormal data distribution. The significance level was $\mathrm{p}<0.05$.

\section{Results}

Vitamin D attenuated vascular remodeling, but induced ET-1 mRNA expression upregulation

Quantification of lumen areas in intrarenal arteries revealed significantly lower lumen areas in UUO group, which were followed by reduction of lumen and wall area ratio (Figs $1 \mathrm{~A}$ and 1B). However, UUO+VD group had significantly higher lumen areas and LWAR compared to the UUO group. There was no significant difference between the UUO+VD and SO group. Quantitative RT-PCR analysis revealed higher expression of ET-1 mRNA in the UUO group (Fig. 1D). Interestingly, vitamin $\mathrm{D}$ treatment induced significant higher expression of ET-1 mRNA ( $<<0.05$ vs. UUO). UUO group also had significant higher ETAR mRNA expression compared to $\mathrm{SO}(\mathrm{p}<0.05$, Fig. 1E), however there was no difference between UUO and UUO+VD groups.

Higher mRNA expression of ETBR and eNOS associated with ischemia lessening in UUO+VD group

UUO group had significant lower mRNA expression of ETBR and eNOS compared to SO (Figs 2A and $2 \mathrm{~B})$. The increased ET-1 mRNA expression in the UUO+VD group was associated with significantly higher expression of ETBR and eNOS mRNA compared to the UUO group. Quantitative RT-PCR showed reduction of CD31 mRNA expression as a marker of endothelial cells in the UUO group, which revealed ischemic conditions after UUO. On the other hand, higher expression of CD31 mRNA was found in the UUO+VD group compared to UUO (Fig. 2C). This finding might associate with higher expression of VEGF in the VD treated group (Fig. 2D). 


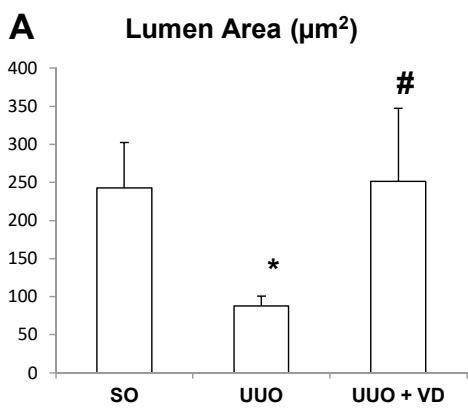

D

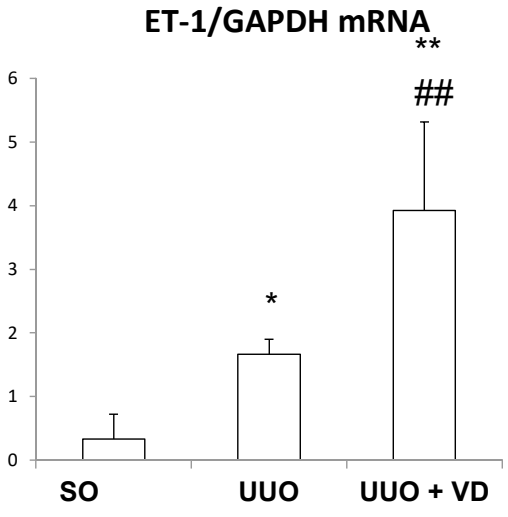

B Lumen/Wall Area
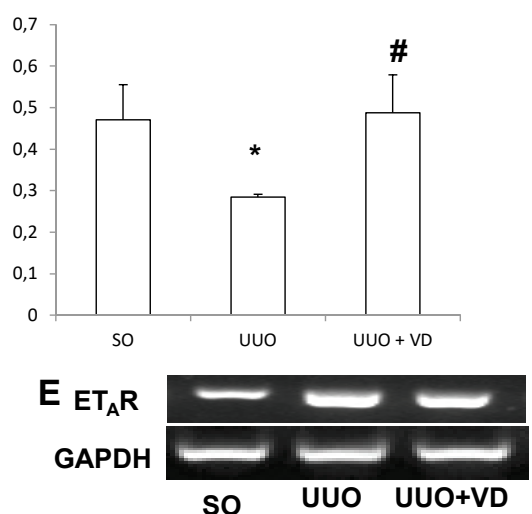

ETAR/GAPDH MRNA

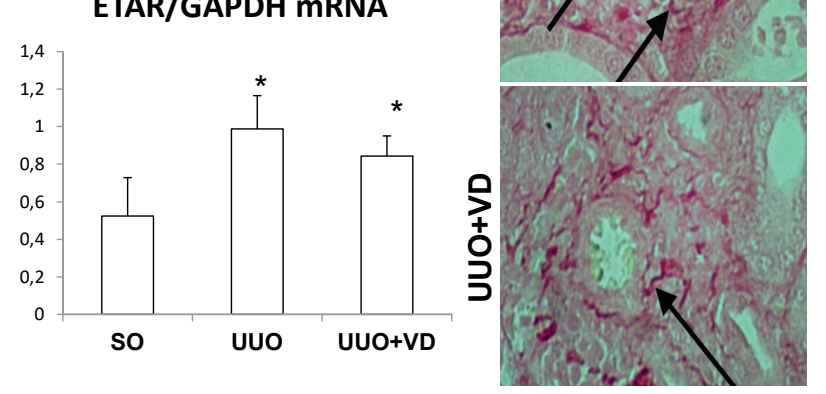

Fig. 1. A, B. Vitamin $D$ ameliorated vascular remodeling. Quantification of lumen area and lumen/wall area ratio showed reduction of lumen area and LWAR in UUO, meanwhile vitamin D treatment ameliorated lumen area and LWAR. C. Representative picture of intrarenal artery based on Sirius Red staining. D. UUO induced a significant increased of ET-1 mRNA expression. Vitamin D treated group had the highest ET-1 mRNA expression. E. Reverse transcriptase-PCR analysis of ETAR expression. ${ }^{*} p<0.05$ vs. SO, $\# p<0.05$ vs. UUO, $* * p<0.01$ vs. SO, \#\#p<0.01 vs. UUO.

A

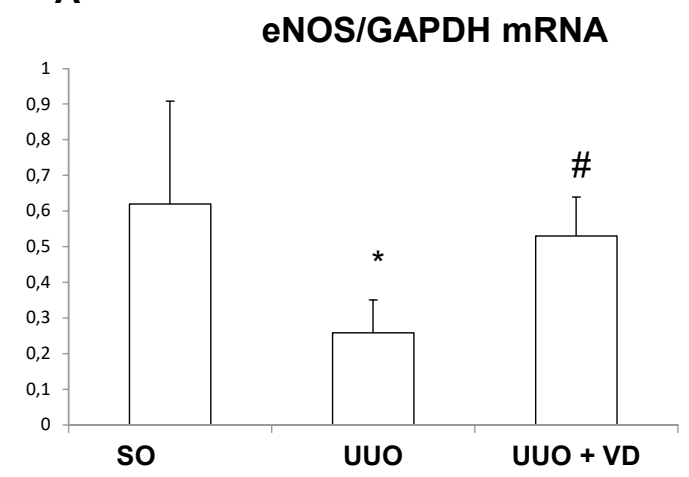

C

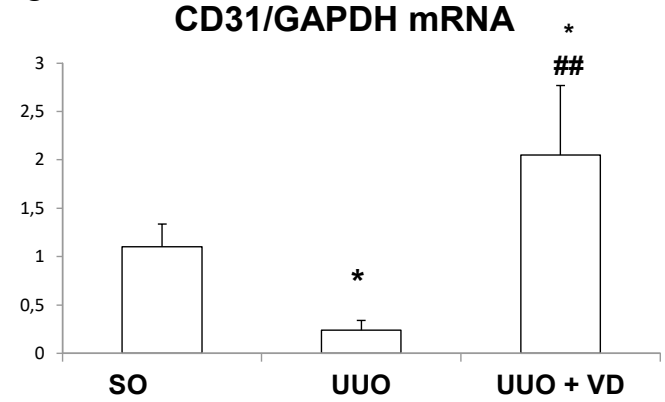

B

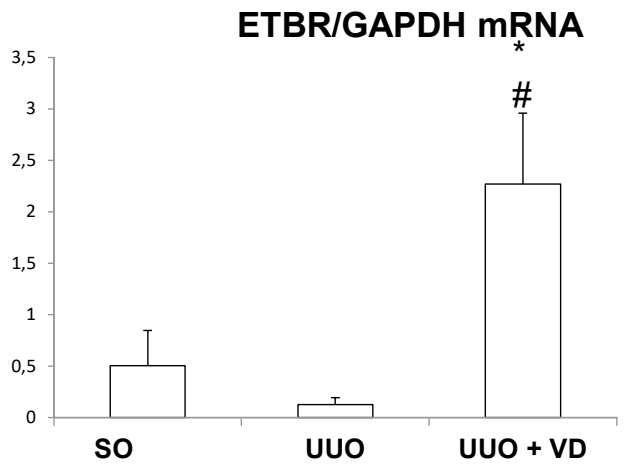

D

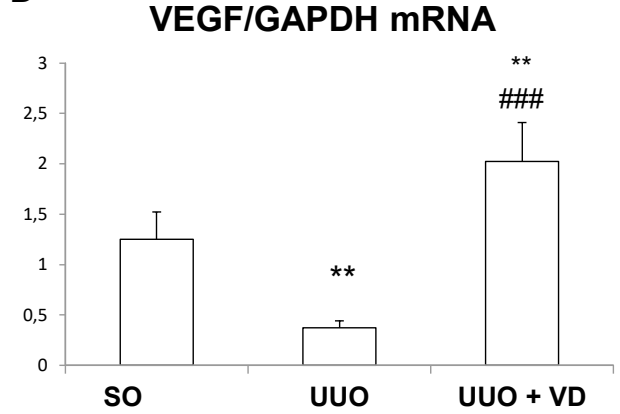

Fig. 2. A. RT-PCR quantification of eNOS mRNA expression. Vitamin $D$ treatment ameliorated eNOS expression after UUO. B. ETBR mRNA expression was quantified by RT-PCR. Vitamin D induced higher expression of ETBR mRNA. C, D. UUO reduced CD31 and VEGF mRNA expression, for the time being vitamin $D$ treatment increased those expressions. ${ }^{*} p<0.05$ vs. SO, $\# p<0.05$ vs. UUO, $* * p<0.01$ vs. SO, \#\#p<0.01 vs. UUO, \#\#\#p<0.001 vs. UUO. 


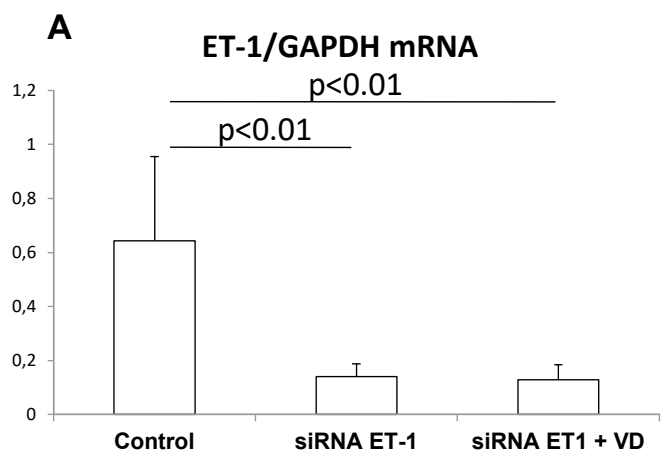

\section{B ENOS/GAPDH MRNA}

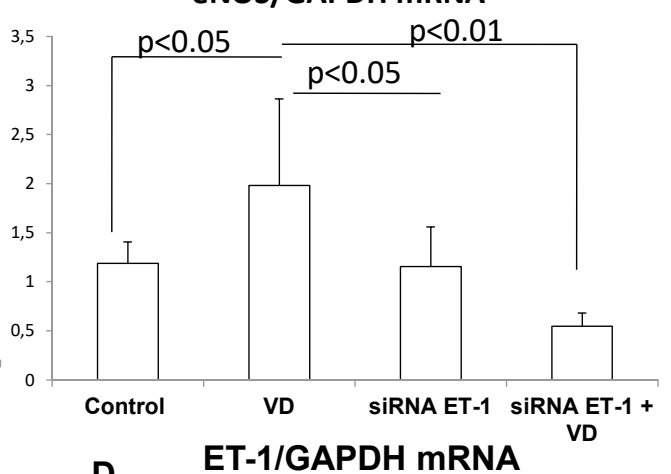

C

ENOS/GAPDH MRNA

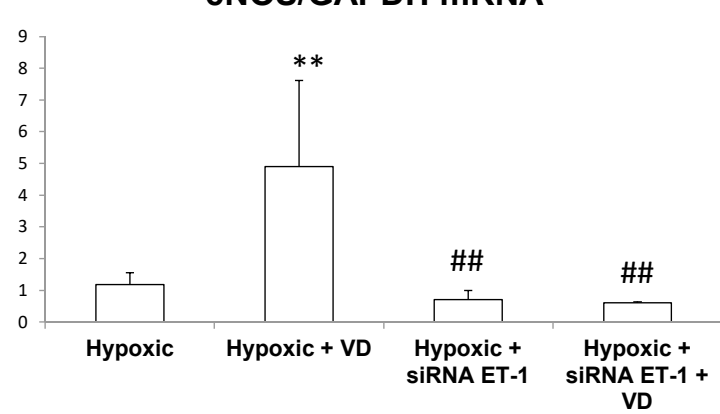

Fig. 3. A. Reduction of ET-1 mRNA expression after siRNA of ET-1 in HUVEC culture. B. Expression of eNOS in HUVEC culture. Vitamin D increased eNOS expression, meanwhile siRNA ET-1 reduced eNOS expression with and without vitamin D treatment. C,D. Expression of eNOS and ET-1 mRNA in HUVEC in hypoxic condition. Vitamin D increased eNOS and ET-1 mRNA expression, on the other hand siRNA of ET-1 reduced eNOS expression with and without vitamin D treatment in hypoxic condition. ${ }^{*} \mathrm{p}<0.05$ vs. hypoxic group, $* * p<0.01$ vs. hypoxic group, \#\#p<0.01 vs. hypoxic+VD group.

Increased expression of eNOS in HUVEC after vitamin D treatment was modulated by ET-1 with and without hypoxic condition

To elucidate the possible modulation of ET-1 in the renoprotective effects of vitamin $\mathrm{D}$, we cultured HUVEC and did siRNA of ET-1, then treated it with vitamin D. The results showed that siRNA of ET-1 (siRNA ET-1 group) produced significantly lower expression of ET-1 mRNA expression ( $\mathrm{p}<0.05$ vs. control) with and without vitamin $\mathrm{D}$ treatment. Quantification of eNOS mRNA expression showed upregulation of eNOS mRNA expression in vitamin D $100 \mathrm{nM}$ treatment $(\mathrm{p}<0.05$ vs. control), further more siRNA of ET-1 reduced eNOS mRNA expression (Fig. 3C).

To examine the effect of hypoxic conditions, we put HUVEC with and without siRNA of ET-1 and vitamin D treatment in hypoxic condition. Quantitative RT-PCR analysis showed higher expression of eNOS and ET-1 mRNA in the vitamin D treatment group. Meanwhile, siRNA of ET-1 reduced eNOS expression in vitamin D treated HUVEC in hypoxic conditions. Our findings seemed to indicate that ET-1 might modulate the effect of vitamin D in inducing eNOS expression.

\section{Discussion}

Continuing our previous result about the renoprotective effects of vitamin D in kidney fibrosis (Arfian et al. 2016), we analyzed the effect of vitamin D in vascular remodeling of intrarenal arteries and eNOS production. Vascular remodeling represents structural changing like hypertrophy or hyperplasia of vascular smooth muscle cells and extracellular matrix components which induce changing of the mechanical function of artery. A resistant artery is an artery that undergoes remodeling, especially in metabolic and cardiovascular diseases (Palen and Matrougui 2008). Here, we reported a reduction of lumen areas in intrarenal resistant arteries with diameter 10-50 $\mu \mathrm{m}$ due to UUO. Structural changing of an artery can be analyzed by the change of vessel diameter (Palen and Matrougui 2008), while remodeling induces reduction of vessel diameter or inward remodeling and increased vessel diameter or outward remodeling (Korshunov et al. 2007). The ratio between wall and lumen area is an important parameter physiologically, because it is also associated with wall thickness (Folkow 1983). Here, we also reported the reduction of lumen and wall area ratio in the UUO group. 
Meanwhile, vitamin D might ameliorate vascular remodeling as shown by increased lumen area and lumen/wall area ratio in the vitamin D treated UUO group.

Endothelin-1 as a potent vasoconstrictor has been reported to play a role in vascular remodeling in many pathological conditions. ET-1 transgenic mice had high wall to lumen ratios with increasing ROS formation (Amiri et al. 2004). ET-1 and ETAR axis may contribute to the vascular remodeling in kidney ischemic/ reperfusion injury. Reduction of ET-1 from EC reduced ETAR expression in vascular smooth muscle cells. Furthermore, deletion of ET-1 in endothelial cells attenuated kidney ischemic conditions with reduction of vascular remodeling and intrarenal arterial wall thickness (Arfian et al. 2012). ET-1 blockers also ameliorate vascular remodeling parameters in mice with diabetic model (Abdelsaid et al. 2014). ETAR antagonist reduced vessel remodeling and increased renal blood flow to $70 \%$ in less than $24 \mathrm{~h}$ after UUO. We observed increasing vascular remodeling with reduction of lumen area and LWAR in UUO might associate with significant higher ET-1 and ETAR mRNA expression. On the other hand, we found significant higher expression of ET-1 mRNA expression with no significant difference of ETAR mRNA expression in UUO+VD group (Fig. 1). Although ET-1 mRNA expression represents the mature ET-1 protein level it may be important also in the next study to examine the ET-1protein level as a priority.

Vasoconstrictor and vasodilator balance might play a role in regulating vascular remodeling in UUO. It is reported that, besides ET-1, NO plays an important role in regulating vessel tonus and remodeling (Bourque et al. 2011, Ye et al. 2003). Renal vasculature also has high sensitivity to NO (Lahera et al. 1991). NO released in the medulla induces local blood flow and improves RBF in CKD model (Savard et al. 2012). Quantification of eNOS mRNA expression revealed vitamin D treatment increased eNOS expression in UUO (Fig. 2A). As a result, we concluded that vitamin $\mathrm{D}$ treatment induced eNOS and ET-1 levels. ET-1 might induce NO production through activation of ETBR expression. We showed here that ETBR also increased after vitamin D treatment (Fig. 2B). However, we could not find significant difference in ETAR expression in UUO group and UUO+VD group (Fig. 1D). Endothelin-1 and NO not only regulates vascular tones of the arteries, but also has complex interaction and function in vascular homeostasis. NO inhibits platelet aggregation, monocyte adhesion and smooth muscle proliferation. Meanwhile ET-1 contributes to vascular remodeling and enhancing vascular remodeling (Rubanyi and Polokoff 1994). Endothelial cells play roles in regulating ET-1 and eNOS production (Sakurai and Sawamura 2003). EC derived NO permanently inhibits the synthesis (Boulanger and Lüscher 1990, Kourembanas et al. 1993) and the vasoconstrictor effects (Goligorsky et al. 1994, Ito et al. 1991) of ET-1. On the other hand ET-1 may stimulate NO production with activation of endothelial ETB receptors in EC (Tsukahara et al. 1994). Reduction of eNOS and upregulation of ET-1 due to UUO in this model might not only induce vascular remodeling, but also endothelial damage that leads to renal damage.

Deletion of eNOS in mice increased severity of kidney injury, meanwhile a NO donor inhibited the process (Morisada et al. 2010). eNOS and VEGF reduction occurs in an obstructed kidney (Sun et al. 2012), furthermore eNOS downregulation becomes one of the early signs of renal fibrosis (Sun et al. 2013a). Downregulation of eNOS induces phosphorylation of Smad3 with JNK modulation and increases fibroblast proliferation and collagen synthesis (Sun et al. 2013a). We assumed that vitamin D effect on eNOS upregulation associated with ET-1 and ETBR mRNA higher expression.

Hypoxia may play some roles in renal fibrosis and induces vascular remodeling. Hypoxia induces vascular remodeling in the pulmonic hypertension model (Blumberg et al. 2003). Interstitial fibrosis in UUO is initiated with hypoxic conditions due to activation of Hypoxia-Inducible Factor-1 $\alpha$ (HIF-1 $\alpha$ ) and Epithelial-toMesenchymal Transition (EMT). Activation of HIF-1 $\alpha$ pathways was signaled by upregulation of HIF-1 in UUO mice model (Higgins et al. 2007). Furthermore, renal ischemia also occurred in CKDs models. Activation of pericyte of microvascular induced myofibroblast formation and fibrosis. Detachment of pericyte from abluminal side of microvessels led to capillary loss and ischemia (Grgic et al. 2012). ET-1 and ETAR expression has also been known to be induced by hypoxic conditions (Li et al. 1994). In this study, UUO induced ischemia condition through reduction of capillaries which was shown by downregulation of CD31 and VEGF mRNA expression (Figs 2C and 2D). On the other hand vitamin D treatment ameliorated CD31 and VEGF mRNA expression in UUO. Vitamin D deficiency (VDD) might induce reduction of renal microvasculature, as shown by a study using VDD model. Inducing ischemic/reperfusion injury led to more reduction of 
microvascular fraction in VDD conditions (Braganca et al. 2016). Vasculature has an important role in vitamin $D$ activation. Normal vitamin D level is important for protecting vascular systems from endothelial dysfunction and vascular diseases, including atherosclerosis (Kienreich et al. 2013). Attenuation of renal ischemia in our study might be due to increased expression of VEGF. VEGF levels are reduced in many models of renal diseases, especially in proximal tubuli. Low VEGF levels with angiogenesis reduction have been reported in renal ablation model, and furthermore VEGF supplementation ameliorates angiogenesis and ischemia (Kang et al. 2001). One in vitro study also reported that vitamin D induces VEGF expression and led to improving angiogenic properties of endothelial progenitor cells (Grundmann et al. 2012). Taken together, vitamin D might improve VEGF and lead to reduction of renal microvascular loss in UUO.

In this study, we elucidated the possible role of ET-1 in eNOS expression in EC culture with and without vitamin D treatment in hypoxic conditions. Using siRNA of ET-1 we could reduce ET-1 mRNA expression (Fig. 3A). Vitamin D $100 \mathrm{nM}$ treatment induced ET-1 and eNOS mRNA expression with and without hypoxic conditions. This finding was associated with higher expression of ET-1 mRNA expression in vitamin D treated HUVEC. The increase of eNOS and ET-1 mRNA assumed that ET-1 might contribute to the effect of vitamin D in eNOS expression. Furthermore, siRNA of ET-1 reduced expression of eNOS although vitamin D was administered in HUVEC. Hypoxic conditions also resulted in reduction of eNOS expression after vitamin D treatment. Vitamin D may induce upregulation of eNOS with and without ET-1 contribution. Martínez-Miguel et al. (2014) showed NO production increased in EC culture after vitamin D treatment was associated with ET-1 production and endothelin converting enzyme-1 (ECE-1) activation. This finding showed ECE-1 activity induces ET-1 production. Our result showed increased levels of ET-1 mRNA expression in vitamin D treated HUVEC culture in hypoxic condition. Hypoxia induces an increased level of ET-1 mRNA expression in kidney ischemic/reperfusion model (Arfian et al. 2012). Our findings support the conclusion that a hypoxic condition might increase ET-1 through upregulation of ET-1 mRNA expression. This result might be different with Martínez-Miguel et al. (2014) which did not induce hypoxic conditions in the EC culture.

Renal endothelial cells injury is induced by many conditions. Hyperglycemia and diabetes play roles in development of microalbuminuria and diabetic nephropathy due to glomerular endothelial dysfunction (Satchell and Braet 2009, Salmon and Satchell 2012, Weil et al. 2012). Endothelial cells of glomerulus protect podocytes from injury and inflammation due to eNOS overexpression (Sun et al. 2013b). Ischemic condition also produces endothelial injury that influence injury of other cells and progression of diseases (Sutton et al. 2002). Interaction between renal endothelial cells and other renal cells also stabilize renal function. Diabetic nephropathy induced glomerular endothelial cell fenestration and detachment of podocyte and lead to diseases progression (Weil et al. 2012). Detachment of pericyte is also responsible for capillary loss and renal ischemia in kidney fibrosis model (Grgic et al. 2012). These result showed specific renal endothelial cells may influence other related cells and lead to specific result and diseases progression. This condition also provides perspective for performing experiments with renal endothelial cells in the future experiment, especially in elucidating vitamin D/ET-1/eNOS interaction in kidney diseases.

Vitamin D through VDR activation induces NO production while inducing eNOS upregulation (Molinari et al. 2011), meanwhile Martínez-Miguel et al. (2014) showed ET-1 and ECE-1 contributed to NO induced vitamin D treatment. Another study in co-culture of osteoblast like cells and HUVEC revealed induction of ET-1 after vitamin D treatment (Wang et al. 1997). We assumed that treatment of vitamin D in this study might induce higher expression of ET-1 and drive eNOS production. ET-1 and ETBR regulates NO production (Liu et al. 2014). We showed in this study that vitamin D treatment induced upregulation of ETBR in UUO model. Thus, the vitamin $\mathrm{D}$ treatment increases eNOSexpression and ameliorated vascular remodeling.

In conclusion, this study highlighted the upregulation of ET-1 and ETBR might relate to eNOS production after vitamin $\mathrm{D}$ treatment in kidney fibrosis. Those upregulation might also associate with attenuating vascular remodeling and ischemia. Further study investigating ETBR and VDR signaling using its blocker are also needed for precise mechanism in many kidney injury models.

\section{Conflict of Interest}

There is no conflict of interest. 


\section{Acknowledgements}

We thank to Mr. Mulyana for supporting of animal handling and sacrifice. This study was funded by Tjacob
Re-entry Postdoctoral Funding from Faculty of Medicine, Universitas Gadjah Mada and International Fellowship Programmee of Takeda Science Foundation 2016-2017.

\section{References}

ABDELSAID M, KACZMAREK J, COUCHA, ERGUL A: Dual endothelin receptor antagonism with Bosentan reverses established vascular remodeling and dysfunctional angiogenesis in diabetic rats: relevance to glycemic control. Life Sci 118: 268-273, 2014.

AHN D, GE Y, STRICKLETT PK, GILL P, TAYLOR D, HUGHES AK, YANAGISAWA M, MILLER L, NELSON RD, KOHAN DE: Collecting duct-specific knockout of endothelin-1 causes hypertension and sodium retention. J Clin Invest 114: 504-511, 2004.

AMIRI F, VIRDIS A, NEVES MF, IGLARZ M, SEIDAH NG, TOUYZ RM, REUDELHUBER TL, SCHIFFRIN EL: Endothelium-restricted overexpression of human endothelin-1 causes vascular remodeling and endothelial dysfunction. Circulation 110: 2233-2340, 2004.

ARFIAN N, EMOTO N, VIGNON-ZELLWEGER N, NAKAYAMA K, YAGI K, HIRATA K: ET-1 Deletion from endothelial cells protects the kidney during the extension phase of ischemia/reperfusion injury. Biochem Biophys Res Commun 425: 443-449, 2012.

ARFIAN N, MUFLIKHAH K, SOEYONO SK, SARI DCR, TRANGGONO U, ANGGOROWATI N, ROMI MM: Vitamin D attenuates kidney fibrosis via reducing fibroblast expansion, inflammation, and epithelial cell apoptosis. Kobe J Med Sci 62: E38-E44, 2016.

ASADA N, TAKASE M, NAKAMURA J, OGUCHI A, ASADA M, SUZUKI N, YAMAMURA K, NAGOSHI N, SHIBATA S, RAO TN, FEHLING HJ, FUKATSU A, MINEGISHI N, KITA T, KIMURA T, OKANO H, YAMAMOTO M, YANAGITA M: Dysfunction of fibroblasts of extrarenal origin underlies renal fibrosis and renal anemia in mice. $J$ Clin Invest 19: 3981-3990, 2011.

BLUMBERG FC, WOLF K, ARZT M, LORENZ C, RIEGGER GA, PFEIFER M: Effects of ET-A receptor blockade on eNOS gene expression in chronic hypoxic rat lungs. $J$ Appl Physiol 94: 446-452, 2003.

BONVENTRE JV, YANG L: Cellular pathophysiology of ischemic acute kidney injury. J Clin Invest 121: 4210-4221, 2011.

BOULANGER C, LÜSCHER TF: Release of endothelin from porcine aorta: inhibition by endothelium-derived nitric oxide. J Clin Invest 85: 587-590, 1990.

BOURQUE SL, DAVIDGE ST, ADAMS MA: The interaction between endothelin-1 and nitric oxide in the vasculature: new perspectives. Am J Physiol Regul Integr Comp Physiol 300: R1288-R1295, 2011.

BRIET M, BURNS KD: Chronic kidney disease and vascular remodelling: molecular mechanisms and clinical implications. Clin Sci 123: 399-416, 2012.

CHEVALIER RL, FORBES MS, THORNHILL BA: Ureteral obstruction as a model of renal interstitial fibrosis and obstructive nephropathy. Kidney Int 75: 1145-1152, 2009.

DE BRAGANÇA AC, VOLPINI RA, MEHROTRA P, ANDRADE L, BASILE DP: Vitamin D deficiency contributes to vascular damage in sustained ischemic acute kidney injury. Physiol Rep 4: e12829, 2016.

FOLKOW B: Structural factors: the vascular wall. Consequences of treatment. Hypertension 5: 58-62, 1983.

GE Y, BAGNALL A, STRICKLETT PK, STRAIT K, WEBB DJ, KOTELEVTSEV Y, KOHAN DE: Collecting duct-specific knockout of the endothelin B receptor causes hypertension and sodium retention. Am J Physiol Renal Physiol 291: 1274-1280, 2006.

GOLIGORSKY MS, TSUKAHARA H, MAGAZINE H, ANDERSEN TT, MALIK AB, BAHOU WF: Termination of endothelin signaling: role of nitric oxide. J Cell Physiol 158: 485-494, 1994.

GRGIC I, DUFFIELD JS, HUMPHREYS BD: The origin of interstitial myofibroblasts in chronic kidney disease. Pediatr Nephrol 27: 183-193, 2012. 
GRUNDMANN M, HAIDAR M, PLACZKO S, NIENDORF R, DARASHCHONAK N, HUBEL CA, VON VERSENHÖYNCK F: Vitamin D improves the angiogenic properties of endothelial progenitor cells. Am J Physiol Cell Physiol 303: 954-962, 2012.

HARTOPO AB, EMOTO N, VIGNON-ZELLWEGER N, SUZUKI Y, YAGI K, NAKAYAMA K, HIRATA K: Endothelin-converting enzyme-1 gene ablation attenuates pulmonary fibrosis via CGRP-cAMP/EPAC1 pathway. Am J Respir Cell Mol Biol 48: 465-476, 2013.

HIGGINS DF, KIMURA K, BERNHARDT WM, SHRIMANKER N, AKAI Y, HOHENSTEIN B, SAITO Y, JOHNSON RS, KRETZLER M, COHEN CD, ECKARDT KU, IWANO M, HAASE VH: Hypoxia promotes fibrogenesis in vivo via HIF-1 stimulation of epithelial-to-mesenchymal transition. J Clin Invest 117: 3810-3820, 2007.

HOCHER B, THONE-REINEKE C, ROHMEISS P, SCHMAGER F, SLOWINSKI T, BURST V, SIEGMUND F, QUERTERMOUS T, BAUER C, NEUMAYER HH, SCHLEUNING WD, THEURING F: Endothelin-1 transgenic mice develop glomerulosclerosis, interstitial fibrosis, and renal cysts but not hypertension. $J$ Clin Invest 99: 1380-1389, 1997.

HUMPHREYS BD, LIN SL, KOBAYASHI A, HUDSON TE, NOWLIN BT, BONVENTRE JV, VALERIUS MT, MCMAHON AP, DUFFIELD JS: Fate tracing reveals the pericyte and not epithelial origin of myofibroblasts in kidney fibrosis. Am J Pathol 176: 85-97, 2010.

ITO S, JUNCOS LA, NUSHIRO N, JOHNSON CS, CARRETERO OA: Endothelium derived relaxing factor modulates endothelin action in afferent arterioles. Hypertension 17: 1052-1056, 1991.

KANG DH, JOLY AH, OH SW, HUGO C, KERJASCHKI D, GORDON KL, MAZZALI M, JEFFERSON JA, HUGHES J, MADSEN KM, SCHREINER GF, JOHNSON RJ: Impaired angiogenesis in the remnant kidney model: I. Potential role of vascular endothelial growth factor and thrombospondin-1. J Am Soc Nephrol 12: 1434-1447, 2001.

KANG DH, KANELLIS J, HUGO C, TRUONG L, ANDERSON S, KERJASCHKI D, SCHREINER GF, JOHNSON RJ: Role of the microvascular endothelium in progressive renal disease. J Am SocNephrol 13: 806-816, 2002.

KIENRICH K, GRÜBLER M, TOMASCHITZ A, SCHMID J, VERHEYEN N, RUTTERS F, DEKKER JM, PILZ S: Indian J Med Res 137: 669-679, 2013.

KORSHUNOV VA, SCHWARTZ SM, BERK BC: Vascular remodeling: hemodynamic and biochemical mechanisms underlying Glagov's phenomenon. Arterioscler Thromb Vasc Biol 27: 1722-1728, 2007.

KOSUGI T, HEINIG M, NAKAYAMA T, MATSUO S, NAKAGAWA T: eNOS knockout mice with advanced diabetic nephropathy have less benefit from renin-angiotensin blockade than from aldosterone receptor antagonists. Am J Pathol 176: 619-629, 2010.

KOUREMBANAS S, MCQUILLAN LP, LEUNG GK, FALLER DV: Nitric oxide regulates the expression of vasoconstrictors on growth factors by vascular endothelium under both normoxia and hypoxia. J Clin Invest 92: 99-104, 1993.

LAHERA V, SALOM MG, MIRANDA-GUARDIOLA F, MONCADA S, ROMERO JC: Effects of NG-nitro-Larginine methyl ester on renal function and blood pressure. Am J Physiol 261: F1033-F1037, 1991.

LI H, CHEN SJ, CHEN YF, MENG QC, DURAND J, OPARIL S, ELTON TS: Enhanced Endothelin-1 and Endothelin receptor gene expression in chronic hypoxia. J Appl Physiol 77: 1451-1459, 1994.

LIN SL, KISSELEVA T, BRENNER DA, DUFFIELD JS: Pericytes and perivascular fibroblasts are the primary source of collagen-producing cells in obstructive fibrosis of the kidney. Am J Pathol 173: 1617-1627, 2008.

LIU S, PREMONT RT, ROCKEY DC: Endothelial nitric-oxide synthase (eNOS) is activated through G-proteincoupled receptor kinase-interacting protein 1 (GIT1) tyrosine phosphorylation and Src protein. J Biol Chem 289: 18163-18174, 2014.

MARTÍNEZ-MIGUEL P, VALDIVIELSO JM, MEDRANO-ANDRÉS D, ROMÁN-GARCÍA P, CANO-PEÑALVER JL, RODRÍGUEZ-PUYOL M, RODRÍGUEZ-PUYOL D, LÓPEZ-ONGIL S: The active form of vitamin D, Calcitriol, induces a complex dual upregulation of endothelin and nitric oxide in cultured endothelial cells. $\mathrm{Am}$ J Physiol Endocrinol Metab 307: E1085-E1096, 2014. 
MIYAGAWA K, EMOTO N, WIDYANTORO B, NAKAYAMA K, YAGI K, RIKITAKE Y, SUZUKI T, HIRATA $\mathrm{K}$ : Attenuation of Doxorubicin-induced cardiomyopathy by endothelin-converting enzyme-1 ablation through prevention of mitochondrial biogenesis impairment. Hypertension 55: 738-746, 2010.

MOLINARI C, UBERTI F, GROSSINI E, VACCA G, CARDA S, INVERNIZZI M, CISARI C: 1a,25-dihydroxycholecalciferol induces nitric oxide production in cultured endothelial cells. Cell Physiol Biochem 27: 661-668, 2011.

MORISADA N, NOMURA M, NISHII H, FURUNO Y, SAKANASHI M, SABANAI K, TOYOHIRA Y, UENO S, WATANABE S, TAMURA M, MATSUMOTO T, TANIMOTO A, SASAGURI Y, SHIMOKAWA H, KUSUHARA K, YANAGIHARA N, SHIRAHATA A, TSUTSUI M: Complete disruption of all nitric oxide synthase genes causes markedly accelerated renal lesion formation following unilateral ureteral obstruction in mice in vivo. J Pharmacol Sci 114: 379-389, 2010.

NATH K: Tubulointerstitial changes as a major determinant in the progression of renal damage. Am J Kidney Dis 20: 1-17, 1992.

PALEN DI, MATROUGUI K: Role of elevated EGFR phosphorylation in the induction of structural remodelling and altered mechanical properties of resistance artery from type 2 diabetic mice. Diabetes Metab Res Rev 24: 651-656, 2008.

RUBANYI GG, POLOKOFF MA: Endothelins: molecular biology, biochemistry, pharmacology and pathophysiology. Pharmacol Rev 46: 325-415, 1994.

SAKURAI K, SAWAMURA T: Stress and vascular responses: endothelial dysfunction lectin-like oxidized-density lipoprotein receptor: close relatiohship with oxidative stress. J Pharmacol Sci 91: 182-186, 2003.

SALMON AH, SATCHELL SC: Endothelial glycocalyx dysfunction in disease: albuminuria and increased microvascular permeability. J Pathol 226: 562-574, 2012.

SATCHELL SC, BRAET F: Glomerular endothelial cell fenestrations: an integral component of the glomerular filtration barrier. Am J Physiol Renal Physiol 296: 947-956, 2009.

SAVARD S, LAVOIE P, VILLENEUVE C, AGHARAZII M, LEBEL M, LARIVIÈRE R: eNOS gene delivery prevents hypertension and reduces renal failure and injury in rats with reduced renal mass. Nephrol Dial Transplant 27: 2182-2190, 2012.

SUN D, WANG Y, LIU C, ZHOU X, LI X, XIAO A: Effects of nitric oxide on renal interstitial fibrosis in rats with unilateral ureteral obstruction. Life Sci 90: 900-909, 2012.

SUN YBY, QU X, LI X, NIKOLIC-PATERSON DJ, LI J: Endothelial dysfunction exacerbates renal interstitial fibrosis through enhancing fibroblast Smad3 linker phosphorylation in the mouse obstructed kidney. PLoS One $\mathbf{8}$ : e84063, 2013a.

SUN YBY, QU X, ZHANG X, CARUANA G, BERTRAM JF, LI J: Glomerular endothelial cell injury and damage precedes that of podocytes in adriamycin-induced nephropathy. PLoS One 8: e55027, $2013 \mathrm{~b}$.

SUTTON TA, FISHER CJ, MOLITORIS BA: Microvascular endothelial injury and dysfunction during ischemic acute renal failure. Kidney Int 62: 1539-1549, 2002.

TSUKAHARA H, ENDE H, MAGAZINE HI, BAHOU WF, GOLIGORSKY MS: Molecular and functional characterization of the non-isopeptide-selective ET(B) receptor in endothelial cells. Receptor coupling to nitric oxide synthase. J Biol Chem 269: 21778-21785, 1994.

VIGNON-ZELLWEGER N, HEIDEN S, MIYAUCHI T, EMOTO N: Endothelin and endothelin receptors in the renal and cardiovascular systems. Life Sci 91: 490-500, 2012.

WANG DS, MIURA M, DEMURA H, SATO K: Anabolic effects of 1,25-dihydroxyvitamin D3 on osteoblasts are enhanced by vascular endothelial growth factor produced by osteoblasts and by growth factors produced by endothelial cells. Endocrinology 138: 2953-2962, 1997.

WANG S, ZENG H, XIE X-J, TAO Y-K, HE X, ROMAN RJ, ASCHNER JL, CHEN J-X: Loss of prolyl hydroxylase domain protein 2 in vascular endothelium increases pericyte coverage and promotes pulmonary arterial remodeling. Oncotarget 7: 58848-58861, 2016.

WEIL EJ, LEMLEY KV, MASON CC, YEE B, JONES LI, BLOUCH K, LOVATO T, RICHARDSON M, MYERS BD, NELSON RG: Podocyte detachment and reduced glomerular capillary endothelial fenestration promote kidney disease in type 2 diabetic nephropathy. Kidney Int 82: 1010-1017, 2012. 
WIDYANTORO B, EMOTO N, NAKAYAMA K, ANGGRAHINI DW, ADIARTO S, IWASA N, YAGI K, MIYAGAWA K, RIKITAKE Y, SUZUKI T, KISANUKI YY, YANAGISAWA M, HIRATA K: Endothelial cell-derived endothelin-1 promotes cardiac fibrosis in diabetic hearts through stimulation of endothelial-tomesenchymal transition. Circulation 121: 2407-2418, 2010.

YE, Q, CHEN S, GARDNER DG: Endothelin inhibits NPR-A and stimulates eNOS gene expression in rat IMCD cells. Hypertension 41: 675-681, 2003. 